\title{
Factors Associated with Pre-hospital Delay before Reperfusion Therapy in Patients with ST-Segment Elevation Myocardial Infarction
}

\author{
Ram Chandra Kafle, ${ }^{\mathrm{a}}$ Navaraj Paudel, ${ }^{\mathrm{b}}$ Girija Shankar Jha, ${ }^{\mathrm{a}}$ Dibya Sharma, ${ }^{\mathrm{c}}$ \\ Vijay Madhav Alurkar ${ }^{\mathrm{d}}$
}

\begin{abstract}
:
Introduction: Cardiovascular disease remains the main cause of death in the world, and myocardial infarction represents the main contributor to this mortality. Timely restoration of myocardial blood flow with reperfusion therapy is crucial. Pre-hospital delay is a major obstacle for early reperfusion therapy and has negative impact on mortality and left ventricle function. Methods: A prospective study was carried in cardiology unit of a medical college from August 2013 to December 2017. Cases of acute ST segment elevation myocardial infarction that have undergone thrombolysis were recruited. Results: Out of 450 patients with ST Elevation Myocardial Infection (STEMI), delayed presentation was seen in $288(64 \%)$ for $>6 \mathrm{hrs}$ and $108(24 \%)$ patients for $>12 \mathrm{hrs}$. The duration from onset of symptoms to the presentation in the emergency room (pre-hospital delay) was $12.66 \mathrm{hrs}(\mathrm{SD}=14.19$, range $=30 \mathrm{~min}$ to $72 \mathrm{hrs})$. The door to needle time was $54 \mathrm{~min}(\mathrm{SD}=24)$ The major factors for pre-hospital delay were misinterpretation of symptoms (59\%) and transportation problems (31\%). Conclusion: Misinterpretation of symptoms remain the most common cause of delayed presentation. Health education for public awareness can reduce the delay. Extension of thrombolytic therapy to district hospital and primary health center level after basic training for medical officer with checklist and collaboration in form of telemedicine with referral cardiac center may have major impact on morbidity and mortality reduction in acute STEMI patients with early reperfusion therapy.
\end{abstract}

Keywords: chest pain, myocardial infarction, pre-hospital delay, thrombolysis

Submitted: 20 May 2018

Accepted: 24 August 2018

Published: 16 September 2018

a - Assistant professor, Department of cardiology, Manipal College of Medical Sciences (MCOMS), Pokhara

b - Associate professor, Department of cardiology, MCOMS, Pokhara

c - Assistant Professor, College of Nursing, MCOMS

d - Professor, Department of cardiology, MCOMS, Pokhara

Corresponding Author:

Ram Chandra Kafle

e-mail: drkafle30@gmail.com

ORCID: https://orcid.org/0000-0002-9840-8009

How to cite this article:

Kafle RC, Paudel N, Jha GS, Sharma D, Alurkar VM. Factors associated with pre-hospital delay before reperfusion therapy in patients with ST-segment elevation myocardial infarction. Journal of Lumbini Medical College. 2018;6(2):5 pages. DOI: 10.22502/jlmc. v6i2.228. Epub: 2018 September 16.

\section{(c) (1)}

Licensed under CC BY 4.0 International License which permits use, distribution and reproduction in any medium, provided the original work is properly cited.

\section{INTRODUCTION:}

Non-Communicable Disease (NCD) is a leading cause of death worldwide. According to the World Health Organization (WHO), "40 million of the 56 million global deaths in 2015 were due to NCDs". Moreover, "48\% of NCDs deaths in lowand middle-income countries in 2015 occurred before the age of 70".[1] Cardiovascular disease remains the main cause of death worldwide, and myocardial infarction represents the main contributor to this mortality. Annually, more than three million people suffer or die from ST Elevation Myocardial Infarction (STEMI) worldwide.[2] Treatment of patients with acute myocardial infarction (MI) is time related.[3] Delay of every minute after STEMI is associated with increasing mortality and morbidity. [4] Prehospital delay is a major contributor to the morbidity and mortality in MI.[5] A landmark study by De Luca et al. showed that every 30 minutes 
prolongation in treatment delay was associated with a relative risk for 1-year mortality of 1.075 . [6] Timely restoration of myocardial blood flow in STEMI optimizes myocardial salvage and reduces morbidity and mortality.[7,8]

Several factors contribute to pre-hospital delay such as age, gender, educational status, and clinical and psychological factors.[9] The total prehospital delay period consists of two components: Time taken by patients to recognize that their symptoms are serious and to contact medical help (decision time) and the time taken from requesting help to hospital admission (home-to-hospital delay). Despite quality improvement efforts to decrease the system delay in starting reperfusion treatment, some percentages of patients receive therapy outside the recommended time interval even in developed countries.[10] While the extent and the determinants of this delay have been well researched in the developed countries, it remains yet to be systematically identified in various developing countries like Nepal, and Nepalese studies are few in this regard. This study was carried out to determine pre-hospital delay and associated factors in patients with acute STEMI.

\section{METHODS:}

A hospital based prospective observational study was carried out in STEMI patients from August 2013 to December 2017. The study was conducted in cardiology unit, department of internal medicine, Manipal College of Medical Sciences, Phulbari-11, Pokhara.

The diagnosis of STEMI was done based on 2013 ACC/AHA guideline and thrombolytic agents were given according to patient party preference after they were given the option of both Streptokinase (STK) and Tenecteplase (TNK). Thromboytic agents were given in patients presented within 12 of chest pain or had clinical or electrocardiographic evidence of ongoing ischemia when given beyond 12 hrs. Hypertension was defined according to JNC-7 criteria , Diabetes Mellitus based on 2013 ADA guideline and Dyslipidemia based on 2013 ACC/AHA guideline.

In all patients, time of delay was established since the onset of symptoms associated with myocardial infarction and the arrival to the emergency department whether they received medical care elsewhere or not. The cases of
STEMI who were eligible for thrombolysis were included in this study. STEMI cases not eligible for thrombolysis, who had undergone primary angioplasty or unable to tell exact timing of chest pain and who presented without chest pain but having angina equivalent symptoms were excluded from the study. In all patients, clinical evolution follow-up was made until discharge.

The data was collected as per the attached proforma. Semi structured questionnaire was used to interview the patient. Collected data were entered into a master chart prepared in Microsoft Excel 2007 which was checked, verified and converted into SPSS 18 version for statistical analysis. Descriptive statistics like mean, percentage, frequency, standard deviation was used to describe characteristics of collected data. Chi-square was applied to find association between prehospital delay with socio-demographic characteristics and cardiac risk factors. $\mathrm{P}$ value less than 0.05 was considered statistically significant.

The study was approved by the Ethical Review Committee (ERC) of Manipal College of Medical Sciences, Nepal. The participants were informed about the purpose of the project, their right to decline participation and to withdraw at any stage of the study. Verbal consent was obtained from the participants. The confidentiality was maintained by removing personal identifiers and information was only used for purpose of the study.

\section{RESULTS:}

Altogether 450 STEMI-diagnosed patients were interviewed from August 2013 to December 2017 giving a response rate of $100 \%$.

Mean age of the patients was 60 yrs $(\mathrm{SD}=13.02)$. There were $319(70.89 \%)$ male and 131 (29.11) female patients. Mean duration of prehospital delay was $12.66 \mathrm{hrs}(\mathrm{SD}=14.19)$. In nearly one fourth of the cases, delay was more than $12 \mathrm{hrs}$ as shown in Table 1.

Several risk factors of MI were present in the patients. Their frequency and percentages are shown in Table 2. More than 2/3rd were smoker and majority (52\%) had hypertension.

More than half $(54.7 \%, \mathrm{n}=246)$ of the patients were treated with tenecteplase as a thrombolytic agent whereas $45.3 \%(n=204)$ were treated with streptokinase. Mean door to needle time was 54 minute $(\mathrm{SD}=24)$. 
Table 1: Prehospital delay in the study population $(n=450)$

\begin{tabular}{ccc}
\hline Duration & $\mathbf{n}$ & $\mathbf{\%}$ \\
\hline$<1 \mathrm{hr}$ & 3 & 0.67 \\
1 to 6 hrs & 159 & 35.33 \\
7 to $12 \mathrm{hrs}$ & 180 & 40 \\
$>12 \mathrm{hrs}$ & 108 & 24 \\
\hline
\end{tabular}

Table 2: Exposure of MI patients to risk factors $(n=450)$

\begin{tabular}{llcc}
\hline \multicolumn{2}{l}{ Characteristics } & n & \% \\
\hline \multirow{2}{*}{ Smoking } & Yes & 312 & 69.3 \\
& No & 138 & 30.7 \\
\multirow{2}{*}{ Hypertension } & Yes & 234 & 52 \\
& No & 216 & 48 \\
\multirow{2}{*}{ Diabetes } & Yes & 72 & 16 \\
Mellitus & No & 378 & 84 \\
\multirow{2}{*}{ Dyslipidemia } & Yes & 72 & 16 \\
& No & 378 & 84 \\
\multirow{2}{*}{ Alcohol } & Yes & 102 & 22.7 \\
& No & 348 & 77.3 \\
\hline
\end{tabular}

Association between pre-hospital delay and various factors is shown in Table 3. It shows that there was a significant association of prehospital delay with age-group and sex of the patient but not with cardiac risk factors like diabetes, hypertension, hypercholesterolemia, smoking, and alcohol intake. Further analysis of relationship between delay and age-group with Bonferroni correction revealed that the relationship was significant with the age group more than $65 \mathrm{yrs}$. This suggests that the people above $65 \mathrm{yrs}$ of age were more likely to be brought to hospital earlier (within $12 \mathrm{hrs}$ ) as compared to other younger age groups.

Table 4 shows the major factors for pre-hospital delay. The most common factor was misinterpretation of symptoms as acid peptic disease (APD) followed by transportation problems.

Table 4: Factors causing pre-hospital delay $(n=450)$

\begin{tabular}{lcc}
\hline Factors & $\mathbf{n}$ & $\mathbf{\%}$ \\
\hline Misinterpreted as APD & 266 & 59.1 \\
Transportation delay & 140 & 31.1 \\
Inter-hospital delay & 31 & 6.9 \\
Reperfusion decision delay & 13 & 2.9 \\
\hline
\end{tabular}

\section{DISCUSSION:}

More than fifty percentage of the patients age ranges from 45-65 yrs with mean of $60 \mathrm{yrs}(\mathrm{SD}=13.02)$ which is similar to the study by Perkins-Porras L. et al,[11] Beig JR. et al,[12] and Ribeiro S. et al,[13] where mean age was $59(\mathrm{SD}=11.2), 57.6(\mathrm{SD}=10.5)$, and 62 yrs $(\mathrm{SD}=13.64)$ respectively. Whereas, a study conducted in China reported the mean age of the patient was found to be $65.68 \mathrm{yrs}(\mathrm{SD}=12.68)$.[14]

Table 3: Association between prehospital delay and different risk factors $(n=450)$

\begin{tabular}{|c|c|c|c|c|}
\hline \multirow{2}{*}{ Characteristics } & \multicolumn{4}{|c|}{ Prehospital delay } \\
\hline & & $\begin{array}{c}<12.66 \mathrm{hrs} \\
n(\%)\end{array}$ & $\begin{array}{c}\geq 12.66 \mathrm{hrs} \\
n(\%)\end{array}$ & Stats \\
\hline \multirow{3}{*}{ Age (yrs) } & $<45$ & 39(81.3) & $9(18.8)$ & \multirow{3}{*}{$\begin{array}{c}X^{2}=6.3, \mathrm{df}=2 \\
\mathrm{p}=0.043\end{array}$} \\
\hline & $45-65$ & $180(78.9)$ & $48(21.1)$ & \\
\hline & $>65$ & $120(69) *$ & $54(31)^{*}$ & \\
\hline \multirow{2}{*}{ Sex } & Female & $78(60.5)$ & $51(39.5)$ & \multirow{2}{*}{$\begin{array}{c}X^{2}=21.51, \mathrm{df}=1 \\
\mathrm{p}<0.001\end{array}$} \\
\hline & Male & 261(81.3) & $60(18.7)$ & \\
\hline \multirow{2}{*}{ Smoking habits } & Yes & $240(76.9)$ & $72(23.1)$ & \multirow{2}{*}{$\begin{array}{c}X^{2}=1.38, \mathrm{df}=1 \\
\mathrm{p}=0.24\end{array}$} \\
\hline & No & $99(71.7)$ & 39(28.3) & \\
\hline \multirow{2}{*}{ Hypertension } & Yes & $174(74.4)$ & $60(25.6)$ & \multirow{2}{*}{$\begin{array}{c}X^{2}=0.25, \mathrm{df}=1 \\
\mathrm{p}=0.62\end{array}$} \\
\hline & No & $165(76.4)$ & $51(23.6)$ & \\
\hline \multirow{2}{*}{ Diabetes } & Yes & $54(75.0)$ & $18(25.0)$ & \multirow{2}{*}{$\begin{array}{c}X^{2}=0.005, \mathrm{df}=1 \\
\mathrm{p}=0.94\end{array}$} \\
\hline & No & 285(75.4) & $93(24.6)$ & \\
\hline \multirow{2}{*}{ Dyslipidemia } & Yes & $57(79.2)$ & $15(20.8)$ & \multirow{2}{*}{$\begin{array}{c}X^{2}=0.68, \mathrm{df}=1 \\
\mathrm{p}=0.41\end{array}$} \\
\hline & No & 282(74.6) & $96(25.4)$ & \\
\hline
\end{tabular}

* Statistically significant cell 
Nearly $1 / 4^{\text {th }}(24 \%)$ of the patients duration of pain (prehospital delay) was $>12$ hrs and mean duration was $12.66 \mathrm{hrs}(\mathrm{SD}=14.19)$ which is similar to the study from Mexico.[15] While a study conducted in China confirmed about the mean delay of $23.58 \mathrm{hrs}(\mathrm{SD}=85.09)$ which is relatively higher than the present study.[14] The present study revealed the median duration of prehospital delay is eight hrs which is comparatively higher than other studies where lesser median delay times were reported in Korea (2.5 hrs),[16] Beijing (2.3 hrs),[17] and Chennai (three hrs).[18]

The present study highlights the door to needle time was $54 \mathrm{~min}(\mathrm{SD}=24)$ which is comparable to the study from South India and Beijing which depicted the median door-to-needle time were 75 and 82 min respectively.[19,20] However, few studies showed significantly lower door to needle time i.e $40 \mathrm{~min}$ and $34 \mathrm{~min}$ respectively.[12,21] The current study enlightened the most commonly used thrombolytic agent was tenecteplase (TNK) $54.7 \%$. Nevertheless, the study conducted in Mexico confirmed streptokinase as a most commonly used lytic agents in $67 \%$ of cases.[15]

Age has been shown to be a determinant of increased prehospital delay in many studies;[22,23] the present study also showed significant association between age-group and prehospital delay. There was significant association between sex of the patient and prehospital delay which is analogous with the result acquired in several studies by Ribeiro $\mathrm{S}$. et al, Taghaddosi M. et al, Angerud KH. et al with a higher proportion of female with longer pre-hospital delay.[13,22,23] The reason being females could not directly activate the transportation system and they had to first inform their husband or family in most cases and then only process of transportation started. While divergent result was obtained in a study by Banos-Gonzalez et al,[15] Farshidi H. et al,[24] and George L. et al,[25] where no significant association was found between sex and prehospital delay. There were no significant associations with other cardiac risk factors such as diabetes, hypertension, hypercholesterolemia, smoking habits similar to the study from London.[11] In contrast to this, some studies have reported the presence of diabetes was associated with increased delay.[12, 25]

The major factors for pre-hospital delay were misinterpretation of symptoms (59\%) and transportation delay (31\%) due to difficult geographical location and non-availability of ambulance or other vehicles alike to the results from Mumbai with misinterpretation of symptoms (45\%) and transportation problems (27\%).[21] A study conducted in London figured out the decision time constituted $60 \%$ of the total pre-hospital delay period, home-to-hospital delay accounted for 40\%.[11]

\section{Limitations:}

This study has some limitation. Although every effort was made to interview patients soon after admission, data may have been affected by recall bias. We could not assess other component of pre-hospital delay like cardiovascular history, patient's attribution of symptoms, clinical and proximal factors, and time of admission, symptom onset and call for assistance. Only the cases of acute ST segment elevation myocardial infarction that have undergone thrombolysis were recruited. Only survivors could be interviewed thus factors that influenced delay in individuals who did not survive ACS may not have been captured.

\section{CONCLUSION:}

Majority of cases in our study presented out of window period of six hours. Misinterpretation of symptoms remain the most common cause of delayed presentation. Health education for public awareness can reduce the delay. Extension of thrombolytic therapy to district hospital and primary health centre level after basic training for medical officer with checklist and collaboration in form of telemedicine with referral cardiac centre may have major impact on morbidity and mortality reduction in acute STEMI patients with early reperfusion therapy.

\section{Acknowledgment:}

All the staffs in cardiology unit and all the patients who participated in the study

\section{Conflict of interest:}

Authors declared that no conflict of interest exists. 


\section{REFERENCES:}

1. Mishra SR, Neupane D, Bhandari PM, Khanal V, Kallestrup $P$. Burgeoning burden of non-communicable diseases in Nepal: a scoping review. Globalization and health. 2015 Dec;11(1):32. DOI: 10.1186/s12992-015-0119-7 PMID: 26178459

2. White HD, Chew DP. Acute myocardial infarction. Lancet. 2008;372(9638):570-84 DOI: 10.1016/S01406736(08)61237-4 PMID: 18707987

3. O'Gara PT, Kushner FG, Ascheim DD, Casey Jr DE, Chung MK, De Lemos JA, Ettinger SM, Fang JC, Fesmire FM, Franklin BA, Granger CB. CF/AHA Task Force. 2013 ACCF/AHA guideline for the management of ST-elevation myocardial infarction: executive summary: a report of the American College of Cardiology Foundation/American Heart Association Task Force on Practice Guidelines. Circulation. 2013 Jan 29;127(4):529-5. DOI: 10.1161/ CIR.0b013e3182742c84 PMID: 23247303

4. McNamara RL, Herrin J, Wang Y, Curtis JP, Bradley EH, Magid DJ, Rathore SS, Nallamothu BK, Peterson ED, Blaney ME, Frederick P. Impact of delay in door-toneedle time on mortality in patients with ST-segment elevation myocardial infarction. The American journal of cardiology. 2007 Oct 15;100(8):1227-32. DOI: 10.1016/j. amjcard.2007.05.043 PMID: 17920362

5. Wu JR, Moser DK, Riegel B, McKinley S, Doering LV. Impact of prehospital delay in treatment seeking on inhospital complications after acute myocardial infarction. Journal of Cardiovascular Nursing. 2011 May 1;26(3):18493. DOI: 10.1097/JCN.0b013e3181efea66

6. De Luca G, Suryapranata H, Ottervanger JP, Antman EM. Time delay to treatment and mortality in primary angioplasty for acute myocardial infarction: every minute of delay counts. Circulation. 2004 Mar 16;109(10):1223-5. DOI: 10.1161/01.CIR.0000121424.76486.20 PMID: 15007008

7. Reimer KA, Jennings RB. The" wavefront phenomenon" of myocardial ischemic cell death. II. Transmural progression of necrosis within the framework of ischemic bed size (myocardium at risk) and collateral flow. Laboratory investigation; a journal of technical methods and pathology. 1979 Jun;40(6):633-44. PMID: 449273

8. Shiomi H, Nakagawa Y, Morimoto T, Furukawa Y, Nakano A, Shirai S, Taniguchi R, Yamaji K, Nagao K, Suyama T, Mitsuoka H. Association of onset to balloon and door to balloon time with long term clinical outcome in patients with ST elevation acute myocardial infarction having primary percutaneous coronary intervention: observational study. BMJ. 2012;3257:1-14. PMID: 22623632

9. Prasantha B, Idris MZ, Ahmad N, Agarwal M, Yadav SC, Singh VK. Determinants of prehospital delay among patients attending cardiac emergency with acute chest pain of cardiac origin in Lucknow district. Int J Adv Res. 2013;1:121-9. Full Text: http://www.journalijar.com/ uploads/2013-10-03_131624_45.pdf

10. Krumholz HM, Herrin J, Miller LE, Drye EE, Ling SM, Han LF, et al. Improvements in door-to-balloon time in the United States, 2005 to 2010. Circulation. 2011;124:103845. DOI: 10.1161/CIRCULATIONAHA.111.044107 PMID: 21859971

11. Perkins-Porras L, Whitehead DL, Strike PC, Steptoe A. Prehospital delay in patients with acute coronary syndrome: factors associated with patient decision time and hometo-hospital delay. European Journal of Cardiovascular Nursing. 2009 Mar;8(1):26-33.

12. Beig JR, Tramboo NA, Kumar K, Yaqoob I, Hafeez I, Rather FA, Shah TR, Rather HA. Components and determinants of therapeutic delay in patients with acute ST-elevation myocardial infarction: A tertiary care hospital-based study. Journal of the Saudi Heart Association. 2017 Jan 1;29(1):714. DOI: 10.1016/j.jsha.2016.06.001 PMID: 28127213
13. Ribeiro S, Gaspar A, Rocha S, Nabais S, Azevedo P, Salgado A, Pereira MA, Correia A. Predictors of pre-hospital delay in patients with ST-segment elevation myocardial infarction. Revista portuguesa de cardiologia: orgao oficial da Sociedade Portuguesa de Cardiologia $=$ Portuguese journal of cardiology: an official journal of the Portuguese Society of Cardiology. 2010 Oct;29(10):1521-32. PMID: 21265494

14. Qian L, Ji KT, Nan JL, Lu Q, Zhu YJ, Wang LP, Liao LM, Tang JF. Factors associated with decision time for patients with ST-segment elevation acute myocardial infarction. Journal of Zhejiang University SCIENCE B. 2013 Aug 1;14(8):754-8. DOI: 10.1631\%2Fjzus.BQICC709 PMID: 23897796

15. Baños-González MA, Henne-Otero OL, Torres-Hernández ME, Torres-López JE, González-Aguila CL, SangeadoSantos $\mathrm{M}$, et al. Factors associated with delay to reperfusion therapy in patients with ST-Segment Elevation Myocardial Infarction in a hospital in the southeast of Mexico. Gac Med Mex. 2016;152(4):495-502. PMID: 27595253

16. Park YH, Kang GH, Song BG, Chun WJ, Lee JH, Hwang SY, Oh JH, Park K, Kim YD. Factors related to prehospital time delay in acute ST-segment elevation myocardial infarction. Journal of Korean medical science. 2012 Aug 1;27(8):8649. DOI: $10.3346 / \mathrm{jkms} .2012 .27 .8 .864$ PMID: 22876051

17. Song L, Yan HB, Yang JG, Sun YH, Hu DY. Impact of patients' symptom interpretation on care-seeking behaviors of patients with acute myocardial infarction. Chinese medical journal. 2010 Jul;123(14):1840-5. PMID: 20819565

18. Rajagopalan RE, Chandrasekaran S, Pai M, Rajaram R, Mahendran S. Pre-hospital delay in acute myocardial infarction in an urban Indian hospital: a prospective study. The National medical journal of India. 2001;14(1):8-12. PMID: 11242708

19. George L, Ramamoorthy L, Satheesh S, Saya RP, Subrahmanyam DK. Prehospital delay and time to reperfusion therapy in ST elevation myocardial infarction. Journal of emergencies, trauma, and shock. 2017 Apr;10(2):64. DOI: 10.4103/0974-2700.201580 PMID: 28367010

20. Song L, Yan HB, Yang JG, Sun YH, Liu SS, Li C, Hu DY. Factors associated with delay of reperfusion-decision for patients with ST-segment elevation myocardial infarction. Zhonghua xin xue guan bing za zhi. $2010 \mathrm{Apr} ; 38(4): 301-5$. PMID: 20654072

21. Khan A, Phadke M, Lokhandwala YY, Nathani PJ. A Study of Prehospital Delay Patterns in Acute Myocardial Infarction in an Urban Tertiary Care Institute in Mumbai. Journal of The Association of Physicians of India. 2017 May;65:24-7. PMID: 28598044. Publisher Full Text

22. Taghaddosi M, Dianati M, Bidgoli JF, Bahonaran J. Delay and its related factors in seeking treatment in patients with acute myocardial infarction. ARYA atherosclerosis. 2010;6(1):35-41. PMID: 22577411. Publisher Full Text

23. Angerud KH, Brulin C, Naslund U, Eliasson M. Longer pre-hospital delay in first myocardial infarction among patients with diabetes: an analysis of 4266 patients in the northern Sweden MONICA Study. BMC cardiovascular disorders. 2013 Dec;13(1):6. DOI: 10.1186\%2F1471-226113-6 PMID: 23356233. Publisher Full Text

24. Farshidi H, Rahimi S, Abdi A, Salehi S, Madani A. Factors associated with pre-hospital delay in patients with acute myocardial infarction. Iranian Red Crescent Medical Journal. 2013 Apr;15(4):312-6. DOI: 10.5812\%2Fircmj.2367 PMID: 24083004. Publisher Full Text

25. Mathews R, Peterson ED, Li S, Roe MT, Glickman SW, Wiviott SD, Saucedo JF, Antman EM, Jacobs AK, Wang TY. Use of Emergency Medical Service Transport Among Patients With St-segment-elevation Myocardial Infarction: Findings From the National Cardiovascular Data Registry Acute Coronary Treatment Intervention Outcomes Network Registry-get With the Guidelines. Circulation. 2011 Jul 12;124(2):154-63. DOI: $10.1161 /$ CIRCULATIONAHA.110.002345 PMID: 21690494. 